\title{
La arquitectura hidráulica de las plantas vasculares terrestres, una revisión
}

\author{
The hydraulic architecture of terrestrial vascular plants, a review \\ Gilberto Alemán-Sancheschúlz,2, Eloy Solano'**, Teresa Terrazas ${ }^{3}$ y Jorge López-Portillo ${ }^{4}$

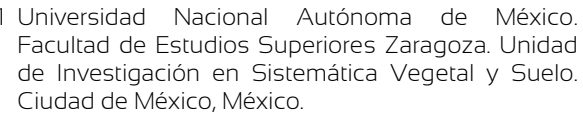

\section{RESUMEN}

El transporte de agua en las plantas vasculares terrestres es pasivo y está determinado por la transpiración o pérdida de agua a través de las hojas. La teoría de la cohesión-tensión es la más aceptada para explicar este proceso, y se complementa con la analogía de la ley de Ohm, que analiza el flujo del agua como un proceso catenario. La resistencia al estrés hídrico y a la cavitación está fuertemente asociada con las características anatómicas del xilema, de las punteaduras intervasculares y de sus membranas, estas últimas se alteran en función de las propiedades químicas de la solución acuosa que fluye a través de ellas. Con base en estas premisas, esta revisión aborda el fenómeno del ascenso del agua en las plantas vasculares terrestres y analiza los conceptos, las teorías y los métodos más usados en el estudio de la arquitectura hidráulica. Además, señala las diferencias en la estructura del xilema y el transporte del agua entre dicotiledóneas y monocotiledóneas.

PALABRAS CLAVE: cavitación, cohesión-tensión, estrés hídrico, potencial hídrico, transporte de agua en las plantas, xilema.

\section{ABSTRACT}

The water transport in terrestrial vascular plants is passive and is determined by the transpiration or loss of water through the leaves. The cohesion-tension theory is the most accepted to explain this process, which is complemented by the Ohm's law analogy, which analyzes the flow of water as a catenary process. Resistance to water stress and cavitation is strongly associated with the anatomical characteristics of the xylem, the intervessel pits, and their membranes, the latter being altered depending on the chemical properties of the aqueous solution that flows through them. Based on these premises, this review addresses the phenomenon of ascent of water in terrestrial vascular plants and analyzes the concepts, theories, and methods most used in the study of hydraulic architecture. In addition, it points out the differences in xylem structure and water transport between dicots and monocots.

KEYWORDS: cavitation, cohesion-tension, water stress, water potential, water transport in plants, xylem.

\section{INTRODUCCIÓN}

El transporte del agua en las plantas ocurre principalmente sin gasto de energía en dirección axial y radial, generalmente a través de la red de conductos formados por las células especializadas en la conducción del agua, conocidos como elementos traqueales que se clasifican en elementos de vaso y traqueidas, los primeros se comunican entre sí en sus extremos y porciones laterales, las segundas son células alargadas conectadas entre ellas en sus costados; a través de estas conexiones fluye el agua desde la raíz hasta las hojas en un gradiente de presiones negativas (Fig. 1). Estas células forman parte del xilema, tejido especializado en la conducción de agua, el soporte y almacenamiento de sustancias. La solución acuosa que es transportada por este sistema también contiene hormonas, proteínas, minerales y otros nutrimentos en pequeñas cantidades (Buhtz, Kolasa, Arlt, Walz y Kehr, 2004). 


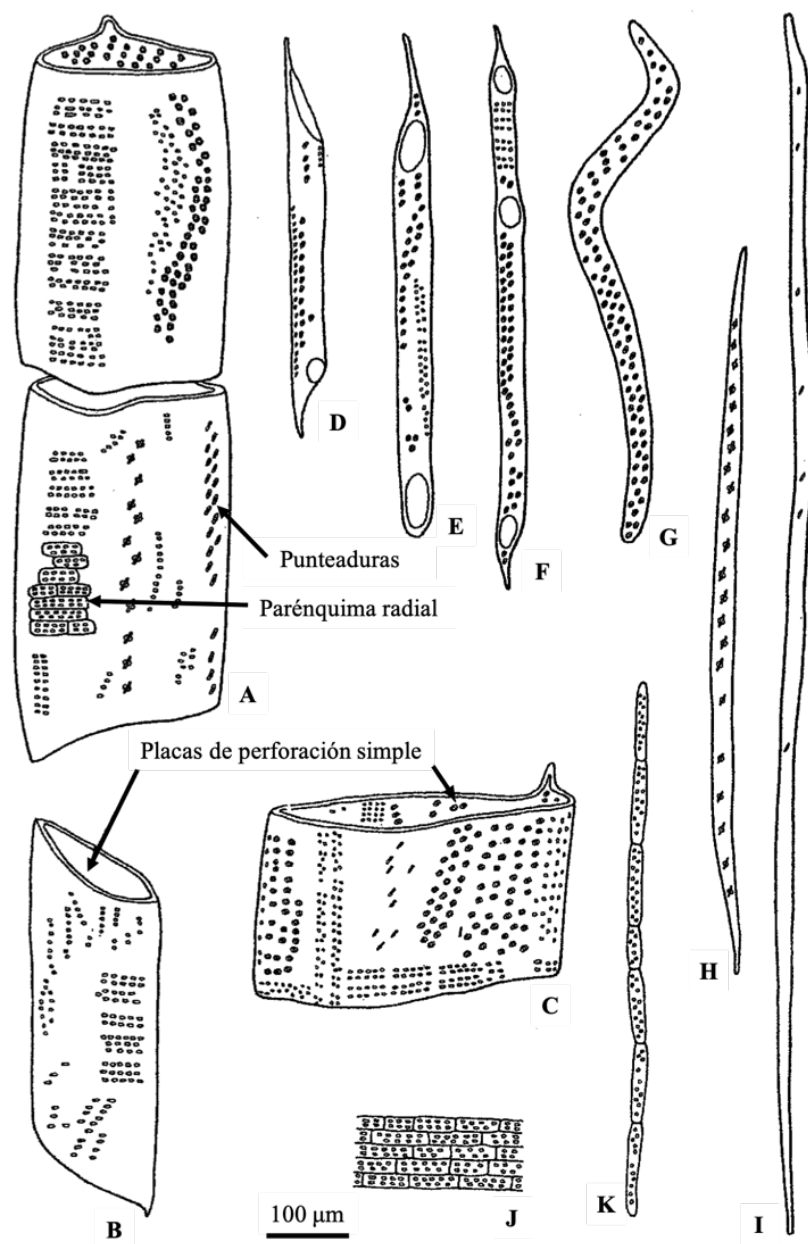

FIGURA 1. Tipos de células del xilema secundario de Quercus sp. A-C) Elementos de vaso anchos. D-F) Elementos de vaso estrechos. G) Traqueida. H) Fibrotraqueida. I) Fibra libriforme. J) Parénquima radial. K) Parénquima axial (Modificada de Evert, 2006).

La capacidad que tienen las plantas para transportar el agua determina las tasas de fotosíntesis, crecimiento y acumulación de materia viva; esta actividad metabólica depende de su contenido de agua: si disminuye, ocasiona pérdida de turgencia, cese del crecimiento, cierre de los estomas, reducción de la tasa fotosintética, marchitamiento y muerte (Taiz y Zeiger, 2012). El estudio de la arquitectura hidráulica contribuye al conocimiento de la fisiología de las comunidades vegetales, en relación con el ambiente en el cual se desarrollan. Por tanto, en esta revisión se analizan los conceptos básicos y algunas técnicas para comprender el fenómeno del ascenso del agua en las plantas vasculares.

\section{RELACIONES HÍDRICAS Y ARQUITECTURA HIDRÁULICA, UN POCO DE HISTORIA}

La primera publicación donde se indica que las plantas absorben agua del suelo se remonta al siglo XVI. En De Plantis Libri XVI (1583), Andrea Cesalpino afirmó que los materiales nutritivos para el desarrollo de las plantas eran absorbidos del suelo por las raíces, y que, transportados por las venas, ascendían por el tallo para producir los frutos. Propuso que la fuerza responsable de este movimiento se encontraba en la médula y la llamó "calor vital". En el siglo XVII, Marcello Malpighi describió e ilustró los vasos del xilema, señaló que aireaban los tejidos, de manera análoga a los "elementos traqueales" del sistema respiratorio de los 
artrópodos (Jansen y Schenk, 2015). Grew (1682) sugirió que los vasos transportaban la savia y que las células de la médula impulsaban el transporte del agua.

En Vegetable staticks: or, an account of some statical experiments on the sap in vegetables (1727), Stephen Hales describió los mecanismos de absorción y flujo radial del agua, la interconexión lateral de los vasos y la entrada de aire. Además, estableció que la transpiración de las hojas determina el movimiento del agua a través de los vasos (Fig. 2). Durante el siglo XIX, algunos autores consideraban que el agua no se movía a través del lumen de los vasos, sino por sus paredes celulares o por los espacios intercelulares (Jansen y Schenk, 2015).

A finales del siglo XIX y principios del XX, surgieron varias interpretaciones acerca de la presencia de burbujas de aire en el xilema. Por ejemplo, que el transporte del agua en las células conductoras del xilema ocurría como cadenas de burbujas alternadas con columnas de agua (denominadas "cadenas de Jamin"; Ewart, 1908), o que las burbujas adheridas a las paredes de los vasos participaban en el transporte de agua (Laschimke, Burger y Vallen, 2006), y que la vulnerabilidad del xilema a la formación de burbujas era mayor de lo que se ha registrado actualmente (Maherali, Pockman y Jackson, 2004; Wheeler, Huggett, Tofte, Rockwell y Holbrook, 2013).

Existen dos publicaciones que constituyeron avances fundamentales en el estudio de las relaciones hídricas de las plantas, una de ellas es Transpiration and the ascent of sap in plants (1914), de Henry H. Dixon, en ella argumenta que cuando la presión positiva de las raíces no actúa y las hojas transpiran, la cohesión del agua explica la transmisión de la tensión hacia las raíces y por tanto, el ascenso del agua a través del xilema; la otra publicación es Xylem structure and the ascent of sap, de Martin H. Zimmermann (1983), en la que presenta una descripción anatómico-funcional del fenómeno de ascenso del agua en las plantas, revisa los modelos y teorías biológicas y físicas que determinan el transporte de este líquido desde las raíces hasta las hojas, y explica los mecanismos que hacen disfuncional al xilema.

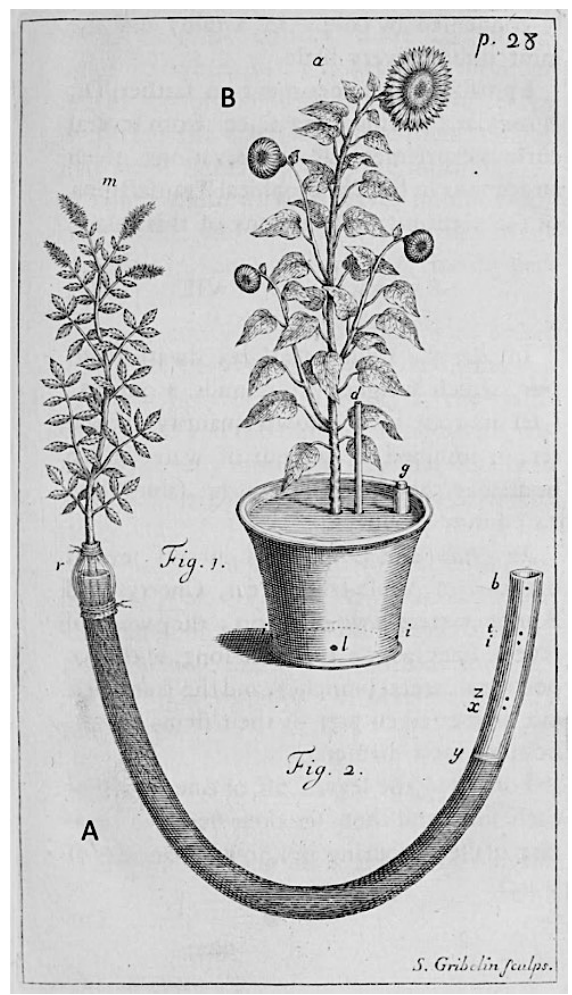

FiguRA 2. Experimentos realizados por Stephen Hales. Registro de la transpiración. A) En una planta de menta. B) En girasol (Modificada de Hales, 1727). 
El desarrollo de este campo del conocimiento en países de habla hispana es más reciente. Martínez-Vilalta y Piñol (2003) explican el fenómeno del transporte de agua a través del xilema y la disfunción de este tejido debido al estrés hídrico en términos de las hipótesis más aceptadas. Ángeles-Álvarez (2013), discute algunas generalidades del fenómeno de ascenso del agua en las plantas vasculares y ofrece una reseña histórica de esta temática.

\section{¿QUÉ ES LA ARQUITECTURA HIDRÁULICA?}

Se define como la estructura del sistema conductor de agua usado por las plantas para distribuirla a través del sistema raíz-tallo-hoja (Tyree y Ewers, 1991; López-Portillo, Ewers, Ángeles y Fisher, 2000). De acuerdo con Cruiziat, Cochard y Améglio (2002), la arquitectura hidráulica integra la teoría de la cohesión-tensión del ascenso del agua y la ley de Ohm, considerando esta última como una analogía eléctrica que trata del flujo de electrones a través de circuitos eléctricos para modelar la transferencia del agua en el continuo sueloplanta-atmósfera (CSPA).

La arquitectura hidráulica también incluye características del sistema conductor, como la longitud y el diámetro de sus células y vasos (Domec et al., 2008; Chave et al., 2009). El triple compromiso (tradeoff) de la anatomía del xilema, basado en la división de las funciones de este tejido, transporte de agua, soporte mecánico y almacenamiento de sustancias, explica la evolución del sistema conductor en términos de diferentes soluciones adaptativas a problemas de estructura y función. Por tanto, hay un compromiso entre la eficiencia y seguridad del transporte del agua, el cual considera que la eficiencia en la conducción de agua es inversamente proporcional a la resistencia mecánica y a la disfunción por bloqueo del lumen celular o embolismo (Baas, 2004). Sin embargo, dada la variabilidad de los caracteres anatómicos del tejido conductor del agua en las plantas, es posible que no siempre exista una relación negativa entre la eficiencia y la seguridad en el transporte del agua a través de los elementos traqueales. Gleason et al. (2016) analizaron este compromiso del xilema en 335 especies de angiospermas y no registraron especies donde este tejido fuera eficiente y seguro contra el embolismo, como lo propuso Baas (2004), sin embargo, sí registraron especies con xilema poco eficiente y vulnerable al embolismo; de acuerdo con Gleason et al. (2016), el compromiso entre seguridad y eficiencia del xilema no siempre se cumple, y su relación puede deberse a la especialización del sistema conductor del agua, en función del hábitat y el hábito de las plantas.

La arquitectura hidráulica se puede estudiar mediante el análisis de la estructura del tejido vascular o considerando a la planta como un sistema hidráulico. En el primer caso se analiza la anatomía del xilema, su estructura tridimensional y las características morfométricas de sus células (Tyree y Zimmermann, 2002); en el segundo se estudian los elementos básicos de los sistemas hidráulicos, como la fuerza motriz, los conductos, reservorios y sistemas de regulación (Cruiziat, Cochard y Améglio, 2002).

\section{¿CÓMO ASCIENDE EL AGUA EN LAS PLANTAS? TEORÍA DE LA COHESIÓN- TENSIÓN}

Esta teoría establece que el ascenso del agua a través de los elementos traqueales ocurre bajo tensión, esto permite explicar el ascenso del agua en el interior de las plantas a grandes alturas (Dixon y Joly, 1895). La cohesión intermolecular del agua líquida y su adhesión a las paredes de los elementos traqueales, permiten esta tensión. La teoría de la cohesión-tensión es la más aceptada para explicar el ascenso del agua en el sistema raíz-tallo-hoja (Ángeles et al., 2004). Poco después de su publicación se realizaron estudios que confirmaron la presencia de la tensión en el agua dentro de los elementos traqueales (Renner, 1925; Scholander, Hammel, Bradstreet y Hemmingsen, 1965). La evaporación es la fuerza motriz que ocasiona el ascenso del agua, esta provoca la transpiración en el mesófilo, tejido que se localiza entre la epidermis del haz y el envés de las hojas, excluyendo los haces vasculares, en la región de interfase del agua líquida a vapor. La tensión en las columnas de agua hace que esta ascienda desde las raíces hasta las hojas, al mismo tiempo que se reduce la energía potencial del agua en los elementos traqueales de las raíces y esta entra por difusión; dentro de ellas el agua se mueve a 
través del apoplasto, espacios extracelulares y paredes, y el simplasto, que incluye a las membranas celulares, sus interconexiones y al citoplasma (Fig. 3, Fig. 4). Para el ascenso continuo del agua es necesario que se cumplan las siguientes condiciones: la cohesión de las moléculas de agua debe soportar la tensión, las columnas de agua dentro de las células conductoras deben ser continuas, y la diferencia de presión entre las raíces y hojas tiene que ser suficiente para elevar el líquido a través de toda la altura de la columna (Niklas, 1992; Sane y Singh, 2011).

Schenk et al. (2017) introdujeron a la teoría de cohesión-tensión el efecto de sustancias que alteran la

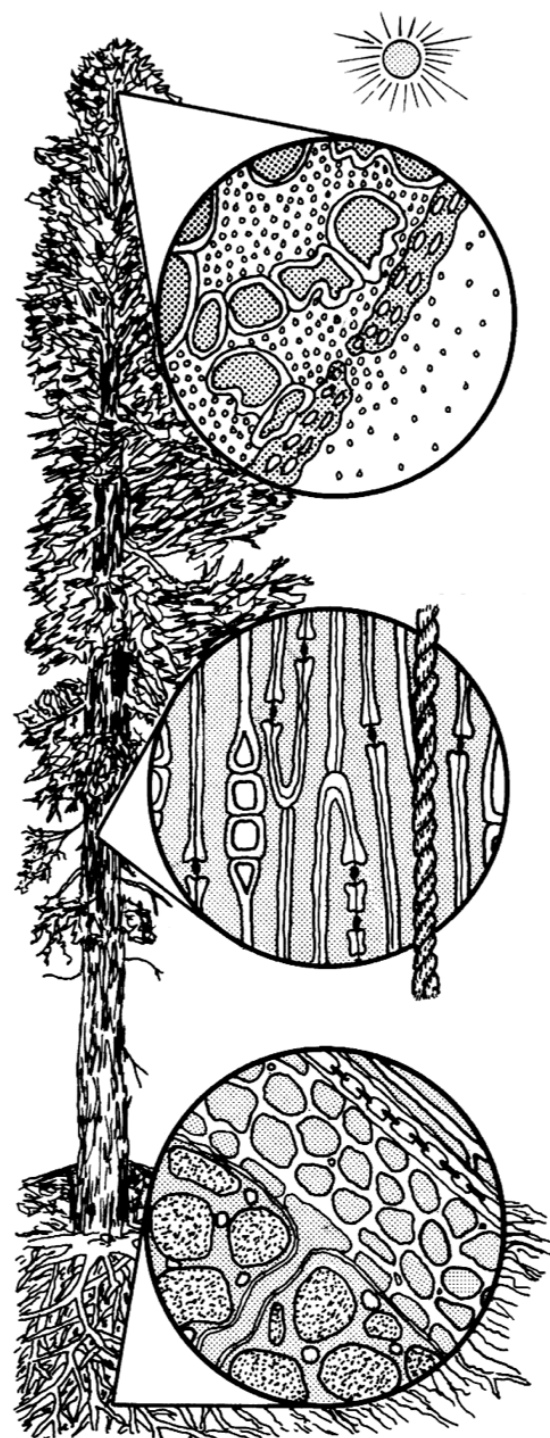

\section{Fuerza motriz: evaporación}

(1) La evaporación en las paredes celulares, debido al potencial hídrico muy negativo del aire,

(2) crea un potencial hídrico muy negativo en:

(2) produce un potencial hídrico muy negativo en:
(a) paredes celulares
(b) protoplastos

(3) La energía que proviene del sol, calienta el agua y el aire.

\section{Cohesión en el xilema:}

(4) Columnas de agua, bajo tensión, se mantienen unidas por cohesión,

(5) debido a las dimensiones capilares de los elementos del xilema.

(6) Si ocurre cavitación, la burbuja no podrá pasar a otro elemento traqueal.

\section{Captación de agua del suelo:}

(7) El potencial hídrico se transfiere a las células de la raíz y al suelo.

(8) Los pelos radicales aumentan la superficie de absorción.

(9) El paso a través de la endodermis puede ocurrir por ósmosis.

Figura 3. Ascenso del agua de acuerdo con la teoría de cohesión-tensión (Modificada de Salisbury y Ross, 1992). 


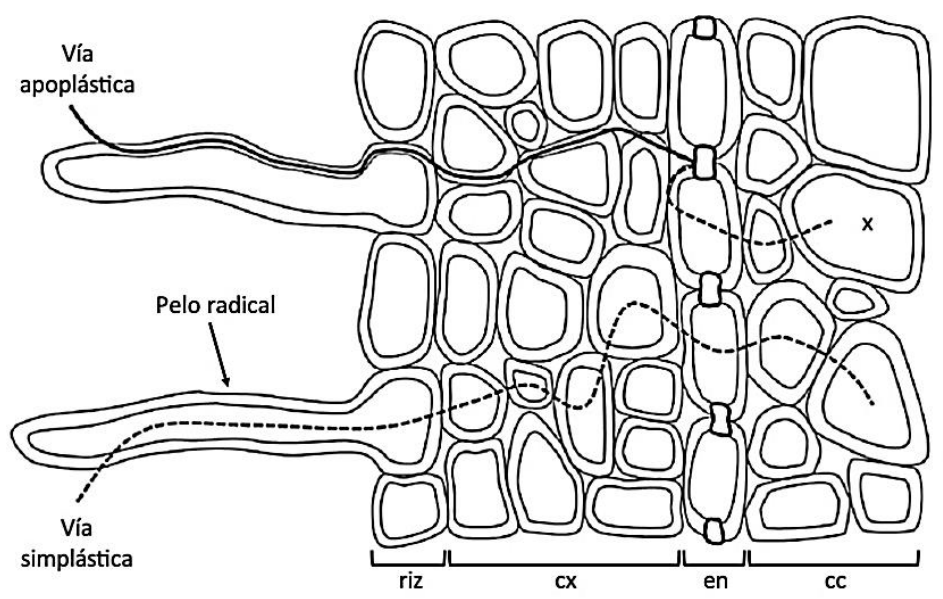

FIGURA 4. Vías de transporte del agua desde el suelo hasta el xilema (cc=cilindro central, $\mathrm{cx}=$ córtex, en=endodermis, riz=rizodermis, $\mathrm{x}=$ xilema) (Modificada de Trakal, MartínezFernández, Vitková y Komárek, 2015).

Algunos autores argumentan que esta teoría tiene limitaciones (Salisbury y Ross, 1992; Kirkham, 2005), y otros han propuesto teorías alternativas (Canny, 1995; Zimmermann, Schneider, Wegner y Haase, 2004). Sin embargo, los argumentos en contra de la cohesión-tensión son inválidos y las teorías alternativas no se han aceptado (Comstock, 1999; Stiller y Sperry, 1999; Ángeles et al., 2004).

\section{ANALOGÍA DE LA LEY DE OHM CON EL FLUJO HÍDRICO}

La ley de Ohm establece que la diferencia de potenciales entre los extremos de un material conductor es proporcional a la intensidad de la corriente que circula por el mismo. Van den Honert (1948) propuso que el flujo de agua que ocurre a través del CSPA, es semejante al flujo de electrones a través de un circuito eléctrico. En esta analogía, el flujo del agua también está determinado por la transpiración de las hojas que produce una diferencia de potenciales hídricos entre el suelo y la superficie foliar.

$\mathrm{Al}$ considerar la analogía de la ley de $\mathrm{Ohm}$, la arquitectura hidráulica del tallo y la hoja se pueden analizar como un diagrama de resistencias (Tyree, Nardini y Salleo, 2000). De este modo, la resistencia al flujo del agua que ofrece cada elemento hidráulico está en función de la diferencia de presiones que induce dicho flujo a través del elemento traqueal y del flujo resultante; la relación que guardan estas variables se expresa con la ecuación, $R=\Delta P / F$, donde: $R$ es la resistencia al flujo, $\Delta P$ la diferencia de presiones y $F$ el flujo resultante. La resistencia al flujo del agua está determinada por las distintas partes del CSPA dentro de la planta, la resistencia puede ser vascular, e involucrar a las membranas de las punteaduras y las placas de perforación; o no vascular, como el movimiento del agua desde la superficie de las raíces hasta el xilema (Nobel, 2009; Tyree y Zimmermann, 2002) (Fig. 5).

\section{CARACTERÍSTICAS CUALITATIVAS DE LA ARQUITECTURA HIDRÁULICA}

Estas características se relacionan con el individuo y son: integración, compartimentación y redundancia (Cruiziat et al., 2002). La primera implica que el sistema vascular de las plantas forma una red que conecta una raíz determinada con una o varias ramas, sin embargo, en algunas monocotiledóneas se distribuye helicoidalmente a lo largo del tallo y su integración ocurre cuando los haces vasculares ascienden desde las raíces, se aproximan al centro del tallo, y después se alejan hacia la periferia ramificándose para vascularizar las hojas (Tyree y Zimmermann, 2002). La segunda indica que el sistema conductor del agua está formado por muchas unidades de conducción que se conectan entre sí a través de las punteaduras y las placas de 


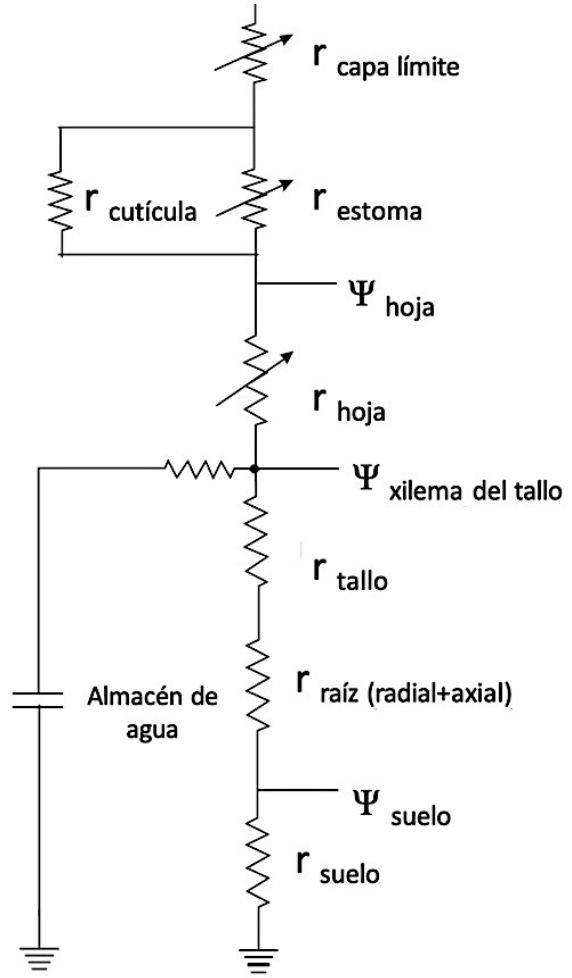

FIGURA 5. Flujo del agua en el continuo suelo-planta-atmósfera, analogía con la ley de Ohm. Las flechas representan resistencias variables $(\Psi=$ potencial hídrico, $r=$ resistencia hidráulica) (Modificada de Blum, 2011).

perforación. La redundancia significa que en cualquier eje (axial o radial) y órgano de la planta están presentes e interconectados varios elementos conductores del xilema; también incluye la porción de la pared celular donde se unen y comunican los elementos traqueales que permiten un flujo de agua continuo. En las monocotiledóneas la redundancia es menor que en las dicotiledóneas debido a que sus elementos traqueales generalmente son solitarios y la comunicación entre el tejido conductor de las hojas es mayor que en el tallo, pues ocurre principalmente por medio del protoxilema que conecta las nervaduras primarias.

La compartimentación se relaciona con la hipótesis de la segmentación hidráulica (Zimmermann, 1983), esta señala que las plantas "sacrifican" segmentos hidráulicamente vulnerables para mantener las partes restantes activas. Tyree y Ewers (1991) modificaron esta hipótesis y la llamaron de segmentación de vulnerabilidad hidráulica, la cual establece que las porciones más distales de las plantas deben ser más vulnerables al embolismo que las zonas basales. Según Ewers, Ewers, Jacobsen y López-Portillo (2007), es posible que la redundancia de los elementos traqueales proporcione mayor seguridad en el transporte del agua, ya que existirían rutas alternativas cuando algunos elementos conductores embolizan.

\section{CARACTERÍSTICAS CUANTITATIVAS DE LA ARQUITECTURA HIDRÁULICA}

El agua en el interior de las plantas fluye a favor de un gradiente de presiones negativas o potenciales hídricos. El potencial hídrico $(\Psi)$ expresa la energía libre del agua por unidad de volumen (Slatyer y Taylor, 1960; Kirkham, 2005; Taiz y Zeiger, 2012). El $\Psi$ se calcula con la ecuación, $\Psi=$ $\Psi_{s}+\Psi_{m}+\Psi_{p}+\Psi_{g}$, donde: $\Psi_{s}, \quad \Psi_{m}, \quad \Psi_{p}$ y $\Psi_{g}$, son los potenciales osmótico (fracción del $\Psi$ debida a la concentración de solutos), mátrico (porción del $\Psi$ atribuible a las interacciones tensiles y cohesivas entre el agua y las partículas del suelo), de presión (contribución de la diferencia de presiones externas al $\Psi$ ) y gravitacional (definido por $\varrho g h$, donde: $\varrho$ es la densidad del agua, $g$ es la aceleración de la gravedad y $b$ es la altura de la columna de agua), respectivamente (Sane y Singh, 2011).

Entre otras técnicas el $\Psi$ se puede determinar con una cámara de presión o con un psicrómetro de termopar (Kirkham, 2005). El primer método fue introducido por Scholander, Hammel, Bradstreet y Hemmingsen (1965) y es el más utilizado para expresar el estado de hidratación de una planta. Los psicrómetros de termopar determinan el $\Psi$ al registrar la humedad relativa a través de la presión de vapor en una cámara pequeña usando técnicas psicrométricas, donde se compara la humedad relativa entre un bulbo húmedo y otro seco (Kirkham, 2005).

El flujo de agua en las plantas es proporcional a la diferencia de potenciales hídricos a través de las estructuras que presentan resistencia a dicho flujo, como las membranas de las punteaduras y los rebordes de las punteaduras areoladas o de las placas de perforación (Nobel, 2009). Tyree y Zimmermann (2002) consideran que el flujo del agua a través de un elemento traqueal es similar 
al de un tubo capilar. La tasa de flujo de agua a través de este tubo es proporcional al gradiente de presión aplicada y a la conductividad hidráulica, esta última es la capacidad de un conducto para permitir el flujo de agua por unidad de área, transversal a la dirección del mismo. La conductividad se obtiene con la ecuación de Hagen-Poiseuille, que establece que el volumen de un fluido que se mueve a través de un conducto cilíndrico por unidad de tiempo, es proporcional a la cuarta potencia de su radio, y se define por la ecuación, $v=\left(\pi p r^{4}\right) /(8 X \eta)$, donde: $v$ es el volumen que se mueve por segundo, $p$ la diferencia de presiones entre los extremos del conducto, $r$ el radio del conducto, $X$ su longitud y $\eta$ el coeficiente de viscosidad (Kirkham, 2005).

Al modificar la ecuación de Hagen-Poiseuille se puede calcular la conductividad hidráulica relativa, al estimar el volumen de agua que fluye a través de los elementos traqueales en función de su radio elevado a la cuarta potencia y del número de elementos traqueales por milímetro cuadrado de tejido en sección transversal (Fahn, Werker y Baas, 1986; Carlquist, 1988), de acuerdo con la ecuación, $\quad C H R=r^{4} \times F V$, donde: $C H R$ es la conductividad hidráulica relativa $\left(\mu^{4} \times 10^{6}\right), r$ el radio y $F V$ la frecuencia o densidad de células conductoras por $\mathrm{mm}^{2}$.

Sperry, Donnelly y Tyree (1988) desarrollaron un método experimental para determinar la conductividad hidráulica y el embolismo por presencia de aire en el xilema de un segmento de tallo, al registrar la tasa del flujo de agua a través de este por unidad de tiempo. La conductividad hidráulica es el cociente entre la tasa de flujo del agua y el gradiente de presión, calculada como, $L=m / \Delta P$, donde: $L$ es la conductividad hidráulica $\left(\mathrm{kg} \mathrm{s}^{-1} \mathrm{~m} \mathrm{MPa}^{-1}\right), m$ la tasa de flujo de agua y $\Delta P$ el gradiente de presión. Si se considera la longitud de la muestra, $L$ expresa la conductividad hidráulica teórica del tallo o $K_{b}$, entonces, $K_{h}=F(d x / d p)$, donde: $F$ es el flujo de agua, $d x$ la longitud del segmento de tallo y $d p$ el gradiente de presión (Tyree y Ewers, 1991; Patino, Tyree y Herre, 1995; Cruiziat et al., 2002).

El cálculo de la $K_{b}$ sobreestima la conductividad hidráulica, pues se supone que el agua fluye por todo el diámetro del segmento de tallo y no solamente por los elementos traqueales. Para obtener un valor de conductividad hidráulica más preciso, es necesario considerar el área del xilema en el cálculo. La conductividad específica se calcula con la ecuación, $K_{S}=K_{h} / S$, donde: $K_{s}$ es la conductividad específica $\left(\mathrm{kg} \mathrm{s}^{-1} \mathrm{~m}^{-1} \mathrm{MPa}^{-1}\right)$ y $S$ el área del xilema (Sperry, Donnelly y Tyree, 1988; Cruiziat et al., 2002). A partir de los valores de $K_{b}$ o $K_{s}$ se obtiene la pérdida porcentual de conductividad hidráulica (PLC), causada por el embolismo debido a la cavitación, mediante la fórmula, $P L C=\left(\left(K_{f}-K_{i}\right) / K_{i}\right) \times 100$, donde: $K_{f}$ es la conductividad final y $K_{i}$ la inicial (Kavanagh y Zaerr, 1997). Sperry et al. (1988) desarrollaron un sistema de tubos en el que se acoplan segmentos de tallo y se registra el flujo hidráulico en una balanza analítica. Melcher et al. (2012) proponen que es posible simplificar el sistema de Sperry, sustituyendo esta balanza por una pipeta o un tubo calibrado que se conecta a un transductor de presión. También existe un modelo comercial del aparato de Sperry denominado "Xyl'em" (Cochard, 2002), que registra el flujo de agua con flujómetros de alta precisión y la $\Delta P$ con transductores de presión electrónicos.

La conductividad específica de la hoja es igual a la $K_{b}$, dividida entre el área foliar de la porción distal del segmento de tallo $\left(A_{l}, \mathrm{~m}^{2}\right)$, y estima la suficiencia hidráulica de una porción de tallo para suministrar agua a las hojas distales del mismo (Tyree y Ewers, 1991). Si se conoce la tasa de transpiración promedio de las hojas y se asume que el contenido de agua es constante, el gradiente de presión a través del segmento de tallo se calcula con la ecuación, $d p / d x=E / K_{l}$, donde: $d p / d x$ es el gradiente de presión a través del segmento de tallo, $E$ la tasa de transpiración promedio de las hojas $\left(\mathrm{kg} \mathrm{s}^{-1} \mathrm{~m}^{-2}\right)$ y $K_{l}$ la conductividad específica de las mismas $\left(\mathrm{kg} \mathrm{s}^{-1} \mathrm{~m} \mathrm{MPa}^{-1}\right)$. Por tanto, entre mayor sea $K_{l}$, menor será el $d p / d x$ necesario para permitir una tasa de transpiración particular (Tyree y Ewers, 1991).

Cuando aumenta la tensión del agua en las células conductoras del xilema ocurre cavitación, fenómeno físico que implica la formación de burbujas por cambios en la presión o en la temperatura de los líquidos (Streeter, Wylie y Bedford, 2000), en este caso, se trata del cambio súbito de agua líquida a vapor dentro de los elementos traqueales. 
Conforme se retira el agua del conducto que ha cavitado, el vapor se expande hasta ocupar todo el interior de la célula, se interrumpe el flujo del agua y se produce embolismo.

\section{Zimmermann (1983) propuso cuatro posibles} mecanismos que inducen la cavitación: siembra de burbujas (air-seeding) (Fig. 6A), siembra de burbujas por medio de una fisura hidrofóbica (Fig. 6B), nucleación homogénea (Fig. 6C) y falla de adherencia hidrofóbica (Fig. 6D). El primero sucede cuando la diferencia de presiones entre las punteaduras de dos elementos traqueales contiguos es suficiente para que una o más burbujas pasen a través de ellas. El segundo se presenta cuando una burbuja estable se localiza en la base de una fisura de la pared de un elemento traqueal, al disminuir la presión, la burbuja es succionada y sale de la fisura. La nucleación homogénea genera espontáneamente vacío en un fluido, es un proceso aleatorio que requiere el movimiento térmico de las moléculas de agua; conforme aumenta la tensión, los enlaces de hidrógeno de estas moléculas se estiran y se debilitan, así, la energía necesaria para romperlos disminuye

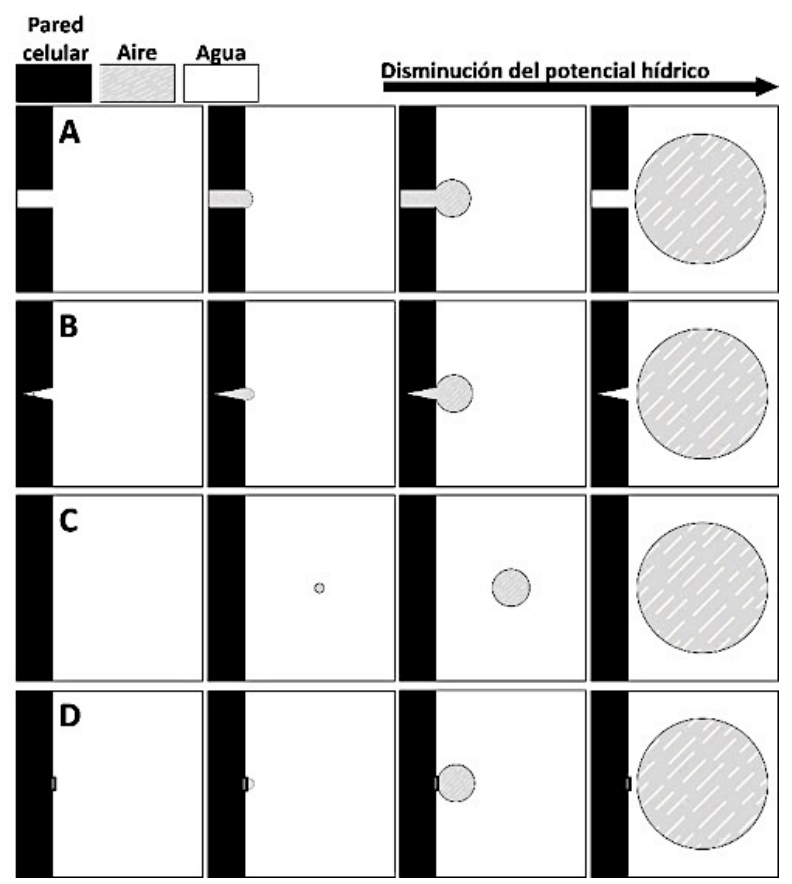

FIGURA 6. Cavitación en los elementos traqueales. A) Siembra de burbujas (air-seeding). B) Siembra de burbujas por medio de una fisura hidrofóbica. C) Nucleación homogénea y D) Falla de adherencia hidrofóbica (Modificada de Tyree y Zimmermann, 2002). y aumenta la probabilidad de que se forme una burbuja. En la falla de adherencia hidrofóbica, los enlaces de hidrógeno del agua se rompen en la porción hidrofóbica de las paredes de los elementos conductores, reduciéndose la energía que une la pared celular con las moléculas de agua.

Con base en las características anatómicas del xilema y de los elementos traqueales, Carlquist (1977) propuso los índices de vulnerabilidad (IV) y mesomorfia (IM), expresados como, $I V=\varnothing V / F V$ e $I M=I V \times L E V$, donde $\emptyset V$ es el diámetro promedio de los elementos traqueales, $F V$ el número de estos por $\mathrm{mm}^{2}$ y $L E V$ su longitud promedio; el primero estima la vulnerabilidad del xilema a la cavitación y el segundo permite inferir si este tejido tiene características de plantas que se desarrollan en ambientes mésicos o xéricos (Carlquist, 1977). Se considera que el xilema es vulnerable a la cavitación si el $I V$ es mayor que uno y resistente si es menor. El xilema es mesomorfo si el $I M$ es mayor a 200, si es menor, será xeromorfo. El xilema de ambientes mésicos tiene elementos de vaso de mayor longitud, menor diámetro, paredes delgadas y placas de perforación escalariformes y el de hábitats xéricos generalmente tiene elementos de vaso más cortos, con mayor diámetro, paredes de mayor grosor y placas de perforación simple.

Hacke, Sperry, Pockman, Davis y McCulloh (2001) desarrollaron el índice de colapso (IC), que permite evaluar la resistencia de los elementos traqueales a la implosión por la tensión asociada con el ascenso del agua; proponen que la resistencia al embolismo por cavitación, el refuerzo de las paredes de los elementos traqueales y la densidad de la madera están relacionadas; argumentan que al aumentar la densidad es mayor la resistencia a la cavitación y se mantiene un intervalo de presiones negativas donde no ocurre el colapso de las células conductoras. Según estos autores la resistencia de los elementos traqueales al colapso está en función del grosor de sus paredes y su diámetro promedio. El $I C$ se calcula con la fórmula, $I C=$ $(E P / \emptyset V)^{2}$, donde: EP es el grosor de dos paredes celulares contiguas y $\emptyset V$ el diámetro promedio de los elementos traqueales. 
La resistencia a la cavitación indica la respuesta de las plantas al estrés hídrico y determina el límite de la presión negativa que se desarrolla en el xilema; también expresa la tensión que tolera una columna de agua antes de cavitar. Se determina mediante la elaboración de una curva de vulnerabilidad, que indica la relación entre la disminución de la conductividad hidráulica del xilema y su $\Psi$ correspondiente (Tyree y Sperry, 1989).

Existen diferentes métodos para obtener los datos del $\Psi$ y PLC necesarios para la construcción de las curvas de vulnerabilidad, uno de ellos es el de deshidratación (Sperry, 1986), donde se deshidratan ramas de una planta para producir presiones progresivamente más negativas en los elementos traqueales, con la correspondiente pérdida de conductividad hidráulica. La curva se construye con los valores de la conductividad y la presión en múltiples segmentos de las ramas, conforme estas se van deshidratando.

Otro método para generar curvas de vulnerabilidad es el de inyección de aire (Cochard, Cruiziat y Tyree, 1992; Salleo et al., 1992; Sperry y Saliendra, 1994), donde se utilizan cámaras de cavitación para forzar la dispersión de las burbujas formadas por este fenómeno, a través de las punteaduras de los elementos traqueales. En esta técnica se considera que la presión necesaria para introducir aire dentro de las células conductoras funcionales es equivalente y opuesta a la presión necesaria para causar cavitación (Hacke, Sperry, Wheeler y Castro, 2006). En este caso, se asume que la cavitación ocurre por siembra de burbujas (Zimmermann, 1983; Sperry et al., 1996).

Otros dos métodos para construir las curvas de vulnerabilidad son el gravitacional y el spin method, en ambos se aplica una fuerza centrífuga a segmentos de tallo donde se induce tensión en el agua que provoca cavitación por medio de máquinas centrífugas especiales (Pockman, Sperry y O’Leary, 1995; Alder, Pockman, Sperry y Nuismer, 1997; Cochard et al., 2005). La tensión generada en el interior de los elementos traqueales por medio de la centrifugación de las muestras es similar al $\Psi$ que se registra con la cámara de presión, en este contexto, las técnicas de centrifugación validan el uso de la cámara de presión y apoyan la teoría de la cohesión-tensión.

Se han empleado diferentes modelos para describir las curvas de vulnerabilidad. Los más utilizados son el exponencial-sigmoidal y el de Weibull (Neufeld et al., 1992; Pammenter y Van der-Willigen, 1998). El primero se describe con la ecuación, $P L C=100 /(1+$ $\exp (a(\Psi-b)))$, donde: PLC es la pérdida porcentual de conductividad hidráulica a un determinado $\Psi, a$ determina la pendiente de la curva y el intervalo de potenciales hídricos a los cuales se pierde la conductividad, 100 representa la pérdida máxima de conductividad y $b$ el coeficiente que determina la posición de la curva en el eje $X$, y expresa el $\Psi$ correspondiente a $50 \%$ del PLC (PLC $50 \%$ o $\mathrm{P}_{50}$ ).

El modelo de Weibull se ajusta a diferentes tipos de curvas y se basa en la función de distribución de probabilidades de Weibull (Rawlings y Cure, 1985; Neufeld et al., 1992; Li et al., 2015). Está definido por la ecuación, $H=\alpha \times e^{[-(\Psi / \Phi) \sigma]}$, donde: $H$ es el porcentaje de máxima conductividad a determinados valores de $\Psi$, a estima la conductividad máxima, $\Phi$ es el $\Psi$ al cual $a$ se reduce a 0.37 y $\sigma$ define la forma de la curva.

De las curvas de vulnerabilidad se obtiene el $P_{50}$ y la presión media de cavitación (PMC) (Hacke et al., 2006), esta última se calcula con la ecuación,

$$
\sum_{P_{0}}^{P_{n}}(\Psi \times P L C) / K_{t o t},
$$

donde: $P_{0}$ es la presión inicial, $P_{n}$ la final y $K_{t o t}$ es la conductividad hidráulica total (Li, Sperry, Taneda, Bush y Hacke, 2008). Ambos parámetros son equivalentes e indican la presión negativa a la que cavitan $50 \%$ de los elementos traqueales funcionales. Los valores más negativos de $\mathrm{P}_{50}$ o PMC, implican mayor resistencia a la cavitación. Sin embargo, para determinar la PMC en las curvas de vulnerabilidad, se grafica la pérdida de conductividad por unidad de cambio en la presión del xilema, en vez de la pérdida de conductividad acumulada (Hacke, Jacobsen y Pratt, 2009). 
Los valores de $\mathrm{P}_{50}$ y PMC son buenos indicadores de la tolerancia de las plantas al estrés hídrico. En plantas leñosas se han registrado valores de $\mathrm{P}_{50}$ de -0.5 hasta -19.0 MPa (Maherali et al., 2004; Scoffoni, Rawls, McKown, Cochard y Sack, 2011; Choat et al., 2012). Sin embargo, los estudios en plantas herbáceas se limitan aproximadamente a 14 especies, con registros de $\mathrm{P}_{50}$ de 0 a $-2 \mathrm{MPa}$ (Stiller y Sperry, 2002; Kocacinar y Sage, 2003), básicamente por la baja conductividad de sus tallos y la fragilidad de sus tejidos.

Es común inferir que las plantas herbáceas son menos resistentes a la cavitación que las leñosas, debido a que los valores de $\mathrm{P}_{50}$ son menos negativos, además, las raíces de las hierbas como Poaceae ejercen presiones positivas (Lens et al., 2016). De acuerdo con Lens et al. (2016), se presentan ciclos diarios de embolismo y recarga de las células conductoras, esto implica que el potencial hídrico de las plantas herbáceas al medio día, es más negativo que su $\mathrm{P}_{50}$, y significa que estas plantas tienen células conductoras vulnerables a la cavitación, caracterizadas por un margen de seguridad hidráulica negativo, que se expresa como la diferencia entre el potenciál hídrico más negativo y el $\mathrm{P}_{50}$. Mientras que el margen de seguridad hidráulica de la mayoría de los árboles es ligeramente positivo (Choat et al., 2012b).

Lens et al. (2016) estudiaron 44 especies de angiospermas herbáceas, observaron que $94 \%$ de los valores de $\mathrm{P}_{50}$ se traslapan con los obtenidos en otros estudios, correspondientes a 301 especies de angiospermas leñosas. El intervalo amplio de estos valores (-0.5 a -7.5 $\mathrm{MPa}$ ) en las plantas herbáceas, indica que no son tan vulnerables a la cavitación y que tienen una capacidad similar a los árboles para resistir potenciales hídricos muy negativos. También indicaron que el $\mathrm{P}_{50}$ de cinco especies de monocotiledóneas, es más negativo que el potencial hídrico registrado al medio día, por tanto, los ciclos de cavitación y recarga, debido a la presión positiva de las raíces, no ocurre habitualmente en este tipo de plantas.

Los parámetros fisiológicos como la conductividad del xilema y la resistencia de este a la cavitación dependen de las características de sus células conductoras, la estructura de las punteaduras y de la composición química de la solución acuosa que fluye a través de ellas (Cochard, Herbette, Hernández, Hölta y Mencuccini, 2010; Lens et al., 2010). El diámetro y el número de elementos conductores por unidad de área están relacionados con la eficiencia de la conductividad hidráulica, el soporte mecánico y con la resistencia del xilema a la cavitación (Baas, 2004).

Las plantas que son más resistentes a la cavitación generalmente tienen elementos conductores de menor longitud, índices de vulnerabilidad y mesomorfia más bajos, paredes de los elementos traqueales más gruesas y mayor resistencia al colapso (Lens, Endress, Bass, Jansen y Smets, 2009). En cambio, las de ambientes xéricos tienen más vasos, agrupados en mayor número, y rodeados por fibras comparadas con aquellas más vulnerables a la cavitación (Carlquist, 2009).

Lens et al. (2010) evaluaron la importancia de la estructura de las punteaduras, como el grosor de su membrana, porosidad y la profundidad de su cámara en relación con la resistencia a la cavitación. Mostraron que en cinco especies de Acer (Aceraceae), más que el número, la estructura de las punteaduras tiene mayor influencia en la PMC. Las especies estudiadas más resistentes a la cavitación tienen cámaras de las punteaduras menos profundas, punteaduras con membranas más gruesas y poros más pequeños que las especies más vulnerables. Registraron que las especies con una PMC más negativa tienen un área mayor de pared celular ocupada por punteaduras, y en general en estas especies el diámetro de los vasos no se relaciona con la PMC. Las especies de Acer menos resistentes a la cavitación tienen una conductividad específica inicial mayor que aquellas con una PMC más negativa, por tanto, la resistencia a la cavitación es mayor y el xilema presenta menor conductividad específica.

Las membranas de las punteaduras son paredes celulares primarias modificadas, están constituidas de microfibrillas de celulosa embebidas en una matriz gelatinosa, conformada por hemicelulosa, enzimas y pectinas hidratadas (Salazar y Gamboa, 2013). Las pectinas son heteropolisacáridos con cinco dominios, uno de ellos es el homogalacturonano (Willats, McCartney, Mackie y Knox, 2001), que es susceptible de enlazarse con cationes 
de calcio como consecuencia de la acción de la enzima pectin metil esterasa (PME) (Pelloux, Rusterucci y Mellerowicz, 2007). Estas pectinas se encuentran en las membranas de las punteaduras intervasculares y son particularmente comunes en las punteaduras areoladas (Hafren, Daniel y Westermark, 2000); el calcio que se les une afecta la elasticidad de la pared celular (Derbyshire, McCann y Roberts, 2007), por tanto, es posible que se relacione con el proceso de cavitación por siembra de burbujas y con la resistencia a la misma. El flujo del agua a través de las membranas de las punteaduras ocurre debido a una pequeña diferencia de presiones a través de ellas, durante este flujo las membranas están relajadas. Durante el proceso de cavitación por siembra de burbujas, aumenta el gradiente de presiones entre las membranas de dos vasos contiguos, estas se deforman, se estiran, sus poros aumentan de diámetro y ocurre la cavitación (Herbette y Cochard, 2010).

Herbette y Cochard (2010) registraron que en Fagus sylvatica (Fagacaeae), con el aumento de la alcalinidad del agua que fluye a través de sus vasos, disminuye la resistencia a la cavitación; de acuerdo con sus resultados, remover el calcio de la pared celular modifica la elasticidad de las membranas de las punteaduras, disminuye la resistencia a la cavitación y no se altera la conductividad hidráulica.

Cochard et al. (2010) señalaron que la composición iónica del agua que fluye a través de los elementos traqueales induce cambios en la conductividad, pero no necesariamente afecta la resistencia a la cavitación. Si se altera la concentración de iones de la solución acuosa que fluye a través de las células conductoras, las pectinas de las membranas de las punteaduras se pueden dilatar o contraer y ocasionan un cambio reversible en la resistencia al flujo del agua (Zwieniecki, Melcher y Holbrook, 2001). La dilatación de las pectinas determina las dimensiones de los microcanales de las membranas de las punteaduras a través de las cuales fluye el agua y también se relaciona con la resistencia al flujo de esta. Sin embargo, las alteraciones estructurales de los poros de las membranas no afectan la resistencia a la cavitación, pues aún dilatados, no son suficientemente grandes para permitir el paso de burbujas
(Shane, McCully y Canny, 2000; Choat, Ball, Luly y Holtum, 2003).

La variación en la conductividad hidráulica como consecuencia de la composición iónica del agua se conoce como "efecto iónico" (Nardini, Dimasi, Klepsch y Jansen, 2012), y sirve para regular el flujo hídrico a través de los elementos traqueales (Cochard et al., 2010). La hipótesis original establece que los cambios en el volumen de la matriz de pectinas en las membranas de las punteaduras son responsables de las modificaciones del tamaño de los poros de estas (Van Doorn, Hiemstra y Fanurakis, 2011). El efecto iónico se relaciona con diversas funciones de las plantas, entre ellas, la evasión al estrés hídrico por medio de la regulación de la conductividad y la compensación de la pérdida de la misma por cavitación (Trifilò, Nardini, Raimondo, Lo Gullo y Salleo, 2011).

\section{ARQUITECTURA HIDRÁULICA DE LA HOJA}

La conductancia de las hojas $\left(k_{i}\right)$ es una medida de la eficiencia del transporte del agua a través de estas y es inversa a la resistencia $\left(r_{l}\right)$. La $k_{l}$ es la relación entre la diferencia de potenciales hídricos con la tasa de flujo del agua a través del peciolo, las nervaduras y el parénquima, hacia los sitios donde ocurre evaporación (Sack y Holbrook, 2006). La conductancia de las hojas se calcula con la ecuación, $k_{l}=F_{l} / \Delta \Psi_{l}$, donde: $F_{l}$ es la tasa de flujo y $\Delta \Psi_{l}$ la diferencia de potenciales hídricos. La $k_{l}$ influye en el transporte del agua a través de toda la planta, pues la resistencia de los estomas a la difusión de vapor hacia la atmósfera, generalmente es mayor que la resistencia al flujo del agua en la planta (Cowan, 1972). En este sentido, el proceso de difusión determina la tasa de transpiración que depende de las conductancias estomática y de la capa límite, se expresa en mmol $\mathrm{m}^{-2} \mathrm{~s}^{-1}$, también depende de la diferencia de presión de vapor entre la hoja y la atmósfera. En las dicotiledóneas el agua se mueve desde los elementos traqueales del tallo hacia el peciolo o hacia la vaina foliar en las monocotiledóneas y de aquí a las nervaduras primarias (Evert, 2006), el flujo continúa al tejido circundante o a las nervaduras secundarias (Altus, Canny y Blackman, 1985). La mayor parte del volumen de agua que se transpira 
proviene de las nervaduras secundarias, por tanto, los dos tipos de venas funcionan en serie para el transporte del agua (Sack, Cowan y Holbrook, 2003). Los patrones de venación son muy diversos entre especies y entre grandes grupos de plantas, por tanto, varían en su disposición y número de órdenes de venación, así como en el tamaño y la forma de los elementos traqueales de las nervaduras. Estas características determinan la distribución del agua a través de la hoja y, en consecuencia, se considera que la conductividad máxima en la misma se correlaciona con las dimensiones de las células conductoras en las nervaduras primarias (Sack y Frole, 2006).

Una vez que el agua sale del xilema se mueve hacia las células de la vaina del haz vascular, con la participación de las acuaporinas fluye a través del protoplasto de estas células y se transfiere al mesófilo. Las células del parénquima esponjoso tienen mayor área de contacto y son más eficientes en la conducción. Después, el agua se transporta hacia la epidermis por medio de las extensiones de la vaina de los haces; si no están presentes, el agua se desplaza a través del mesófilo, por medio del apoplasto o el simplasto (Martre, Morillon, Barrieu, North y Nobel, 2002; Evert, 2006) (Fig. 7). En las hojas, la evaporación del agua ocurre principalmente en el mesófilo que se encuentra debajo de los estomas, en la epidermis adyacente a estos y también en sus células guarda (Tyree y Yianoulis, 1980).

\section{CONCLUSIONES}

El estudio de la arquitectura hidráulica se ha enfocado en las plantas leñosas; en este contexto, hacen falta más investigaciones de este tipo en plantas herbáceas, principalmente en las monocotiledóneas. Esta temática es importante en el ámbito global, pues el cambio climático está afectando la estabilidad de los ecosistemas, donde las comunidades vegetales están sometidas a regímenes hídricos cambiantes que afectan su productividad y supervivencia.

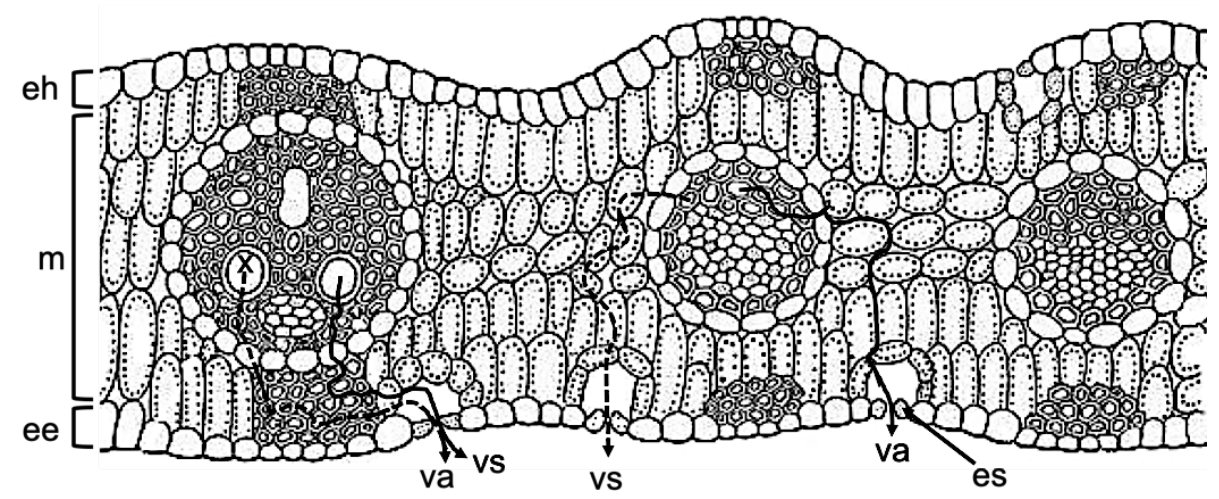

FIGURA 7. Sección transversal de una hoja de monocotiledónea mostrando las vías de transporte del agua, desde el xilema hasta la atmósfera (ee=epidermis del envés, eh=epidermis del haz, es $=$ estoma, $\mathrm{m}=$ mesófilo, va $=$ vía apoplástica, vs $=$ vía simplástica, $\mathrm{x}=$ xilema) (Modificada de Gupta, 2017).

\section{REFERENCIAS}

Alder, N. N., Pockman, W. T., Sperry, J. S., \& Nuismer, S. (1997). Use of centrifugal force in the study of xylem cavitation. Journal of Experimental Botany, 48(3), 665-674. doi: 10.1093/jxb/48.3.665

Altus, D. P., Canny, M. J., \& Blackman, D. R. (1985). Water pathways in wheat leaves. II. Water conducting capacities and vessel diameters of different vein types, and behavior of the integrated vein network. Australian Journal of Plant Physiology, 12(2), 183-199. doi: 10.1071/PP9850183

Ángeles, G. (2013). Plomería vegetal. Ciencia y Desarrollo, Mayo-Junio, 1-2. Ángeles, G., Bond, B., Boyer, J. S., Brodribb, T., Brooks, J. R., Burns, M. J., ... Tyree, M. (2004). The cohesion-tension theory. New Phytologist, 163(3), 451-452. doi: 10.1111/j.14698137.2004.01142.x 
Baas, P. (2004). Evolution of xylem physiology. En A. R. Hemsley \& I. Poole (Eds.), The evolution of plant physiology (pp. 273-291). San Diego, California: Elsevier Academic Press.

Blum, A. (2011). Plant breeding for water-limited environments (1a ed.). Tel Aviv, Israel: Springer Science+Business Media, LLC.

Buhtz, A., Kolasa, A., Arlt, K., Walz, C., \& Kehr, J. (2004). Xylem sap protein composition is conserved among different plant species. Planta, 219(4), 610-618. doi: 10.1007/s00425-004-1259-9

Canny, M. J. (1995). A new theory for the ascent of sap-cohesion supported by tissue pressure. Annals of Botany, 75(4), 343-357. doi: 10.1006/anbo.1995.1032

Carlquist, S. (1977). Ecological factors in wood evolution: a floristic approach. American Journal of Botany, 64(7), 887-896. doi: 10.1002/j.1537-2197.1977.tb11932.x

Carlquist, S. (1988). Comparative wood anatomy. Systematic, ecological, and evolutionary aspects of dicotyledon wood (1 a ed.). New York, USA: Springer-Verlag.

Carlquist, S. (2009). Non-random vessel distribution in woods: patterns, modes, diversity, correlations. Aliso, 27(1), 39-58. doi: 10.5642/aliso.20092701.04

Cesalpino, A. (1583). De plantis libri XVI. Florence, Italy: Giorgio Marescottu.

Chave, J., Coomes, D., Jansen, S., Lewis, S. L., Swenson, N. G., \& Zanne, A. E. (2009). Towards a worldwide wood economics spectrum. Ecology Letters, 12(4), 351-366. doi: 10.1111/j.14610248.2009.01285.x

Choat, B., Ball, M., Luly, J., \& Holtum, J. (2003). Pit membrane porosity and water stress-induced cavitation in four co-existing dry rainforest tree species. Plant Physiology, 131(1), 41-48. doi: 10.1104/pp.014100

Choat, B., Jansen, S., Brodribb, T. J., Cochard, H., Delzon, S., Bhaskar, R., ... Zanne, A. E. (2012). nature11688-s2.

Choat, B., Jansen, S., Brodribb, T. J., Cochard, H., Delzon, S., Bhaskar, R., ... Zanne, A. E. (2012b). Global convergence in the vulnerability of forests to drought. Nature, 491(7426), 752-755. doi: $10.1038 /$ nature11688

Cochard, H. (2002). How to measure xylem embolism with the XYL'EM apparatus. Clermont, France. Retrieved from http://www.bronkhorst.fr/fr/produits/xylem_embolismmeter

Cochard, H., Cruiziat, P., \& Tyree, M. T. (1992). Use of positive pressures to establish vulnerability curves: Further support for the air-seeding hypothesis and implications for pressure-volume analysis. Plant Physiology, 100(1), 205-209. doi: 10.1104/pp.100.1.205
Cochard, H., Damour, G., Bodet, C., Tharwat, I., Poirier, M., \& Améglio, T. (2005). Evaluation of a new centrifuge technique for rapid generation of xylem vulnerability curves. Physiologia Plantarum, 124(4), 410-418. doi: 10.1111/j.1399-3054.2005.00526.x

Cochard, H., Herbette, S., Hernández, E., Hölta, T., \& Mencuccini, M. (2010). The effects of sap ionic composition on xylem vulnerability to cavitation. Journal of Experimental Botany, 61(1), 275-285. doi: 10.1093/jxb/erp298

Comstock, J. P. (1999). Why Canny's theory doesn't hold water. American Journal of Botany, 86(8), 1077-1081. doi: 10.2307/2656968

Cowan, I. R. (1972). Electrical analog of evaporation from, and flow of water in plants. Planta, 106(3), 221-226. doi: 10.1007/BF00388099

Cruiziat, P., Cochard, H., \& Améglio, T. (2002). Hydraulic architecture of trees: main concepts and results. Annals of Forest Science, 59(7), 723-752. doi: 10.1051 / forest:2002060

Derbyshire, P., McCann, M. C., \& Roberts, K. (2007). Restricted cell elongation in Arabidopsis hypocotyls is associated with a reduced average pectin esterification level. BMC Plant Biology, 7(1), 31. doi: 10.1186/1471-2229-7-31

Dixon, H. H. (1914). Transpiration and the ascent of sap in plants. London, United Kingdom: Macmillan.

Dixon, H. H. \& Joly, J. (1895). On the ascent of sap. Philosophical Transactions of the Royal Society of London, 186(1895), 563-576. doi: 10.1098/rstb.1895.0012

Domec, J. C., Lachenbruch, B., Meinzer, F. C., Woodruff, D. R., Warren, J. M., \& McCulloh, K. A. (2008). Maximum height in a conifer is associated with conflicting requirements for xylem design. Proceedings of the National Academy of Sciences of the United States of America, 105(33), 12069-12074. doi: 10.1073/pnas.0710418105

Evert, R. F. (2006). Esau's Plant anatomy (3a ed.). New Jersey, USA.: John Wiley y Sons, Inc.

Ewart, A. J. (1908). The ascent of water in trees: (Second paper). Philosophical Transactions of the Royal Society of London, B, Biological Sciences, 199(1908), 341-392. doi: 10.1098/rstb.1908.0008

Ewers, F. W., Ewers, J. M., Jacobsen, A. L., \& López-Portillo, J. A. (2007). Vessel redundancy: modeling safety in numbers. $I A W A$ Journal, 28(4), 373-388. doi: 10.1163/22941932-90001650

Fahn, A., Werker, E., \& Baas, P. (1986). Wood anatomy and identification of trees and shrubs from Israel and adjacent regions. Jerusalem, Israel: Israel Academy of Sciences and Humanities.

Gleason, S. M., Westoby, M., Jansen, S., Choat, B., Hacke, U. G., Pratt, R. B., ... Zanne, A. E. (2016). Weak tradeoff between xylem safety and xylem-specific hydraulic efficiency across the world's 
woody plant species. New Phytologist, 209(1), 123-136. doi: 10.1111/nph.13646

Grew, N. (1682). The anatomy of plants with an idea of a philosophical history of plants. London, United Kingdom: W. Rawlins.

Gupta, H. (2017). Essay on leaf (with diagrams). Retrieved November 8, 2017, from http://www.biologydiscussion.com/essay/essay-onleaf-with-diagrams-botany/20581

Hacke, U. G., Jacobsen, A. L., \& Pratt, R. B. (2009). Xylem function of arid-land shrubs from California, USA: An ecological and evolutionary analysis. Plant, Cell and Environment, 32(10), 1324 1333. doi: 10.1111/j.1365-3040.2009.02000.x

Hacke, U. G., Sperry, J. S., Pockman, W. T., Davis, S. D., \& McCulloh, K. A. (2001). Trends in wood density and structure are linked to prevention of xylem implosion by negative pressure. Oecologia, 126(4), 457-461. doi: 10.1007/S004420100628

Hacke, U. G., Sperry, J. S., Wheeler, J. K., \& Castro, L. (2006). Scaling of angiosperm xylem structure with safety and efficiency. Tree Physiology, 26(6), 689-701. doi: 10.1093/treephys/26.6.689

Hafren, J., Daniel, G., \& Westermark, U. (2000). The distribution of acidic and esterified pectin in cambium, developing xylem and mature xylem of Pinus sylvestris. LAW A Journal, 21(2), 157-168. doi: $10.1163 / 22941932-90000242$

Hales, S. (1727). Vegetable staticks (1a ed.). London, United Kingdom: W. and J. Innys and T. Woodward.

Herbette, S. \& Cochard, H. (2010). Calcium is a major determinant of xylem vulnerability to cavitation. Plant Physiology, 153(4), 19321939. doi: $10.1104 /$ pp. 110.155200

Jansen, S. \& Schenk, H. J. (2015). On the ascent of sap in the presence of bubbles. American Journal of Botany, 102(10), 1561-1563. doi: 10.3732/ajb.1500305

Kavanagh, K. L., \& Zaerr, J. B. (1997). Xylem cavitation and loss of hydraulic conductance in western hemlock following planting. Tree Physiology, 17(1), 59-63. doi: 10.1093/treephys/17.1.59

Kirkham, M. B. (2005). Principles of soil and plant water relations (1a ed.). Kansas, USA: Kansas State University Elsevier Academic Press.

Kocacinar, F. \& Sage, R. F. (2003). Photosynthetic pathway alters xylem structure and hydraulic function in herbaceous plants. Plant, Cell and Environment, 26(12), 2015-2026. doi: 10.1111/j.13652478.2003.01119.x

Laschimke, R., Burger, M., \& Vallen, H. (2006). Acoustic emission analysis and experiments with physical model systems reveal a peculiar nature of the xylem tension. Journal of Plant Physiology, 163(10), 996-1007. doi: 10.1016/j.jplph.2006.05.004
Lens, F., Endress, M. E., Baas, P., Jansen, S., \& Smets, E. (2009). Vessel grouping patterns in subfamilies Apocynoideae and Periplocoideae confirm phylogenetic value of wood structure within Apocynaceae. American Journal of Botany, 96(12), 21682183. doi: 10.3732/ajb.0900116

Lens, F., Picon-Cochard, C., Delmas, C. E. L., Signarbieux, C., Buttler, A., Cochard, H., ... Delzon, S. (2016). Herbaceous angiosperms are not more vulnerable to drought-induced embolism than angiosperm trees. Plant Physiology, 172(2), 661-667. doi: 10.1104/pp.16.00829

Lens, F., Sperry, J. S., Christman, M. A., Choat, B., Rabaey, D., \& Jansen, S. (2010). Testing hypotheses that link wood anatomy to cavitation resistance and hydraulic conductivity in the genus Acer. New Phytologist, 190(3), 709-723. doi: 10.1111/j.14698137.2010.03518.x

Li, S., Feifel, M., Karimi, Z., Schuldt, B., Choat, B., \& Jansen, S. (2015). Leaf gas exchange performance and the lethal water potential of five European species during drought. Tree Physiology, 36(2), 179192. doi: $10.1093 /$ treephys/tpv117

Li, Y., Sperry, J. S., Taneda, H., Bush, S. E., \& Hacke, U. G. (2008). Evaluation of centrifugal methods for measuring xylem cavitation in conifers, diffuse- and ring-porous angiosperms. New Phytologist, 177(2), 558-568. doi: 10.1111/j.1469-8137.2007.02272.x

López-Portillo, J., Ewers, F. W., Ángeles, G., \& Fisher, J. B. (2000). Hydraulic architecture of Monstera acuminata: evolutionary consequences of the hemiepiphytic growth form. New Phytologist, 145(2), 289-299. doi: 10.1046/j.1469-8137.2000.00578.x

Maherali, H. M., Pockman, W. T., \& Jackson, R. B. (2004). Adaptative variation in the vulnerability of woody plants to xylem cavitation. Ecology, 85(8), 2184-2199. doi: 10.1890/02-0538

Martínez-Vilalta, J. \& Piñol, J. (2003). Limitaciones hidráulicas al aporte de agua a las hojas y resistencia a la sequía. Ecosistemas, 12(1), 1-7.

Martre, P., Morillon, R., Barrieu, F., North, G. B., \& Nobel, P. S. (2002). Plasma membrane aquaporins play a significant role during recovery from water deficit. Plant Physiology, 130(4), 2101-2110. doi: 10.1104/pp.009019

Melcher, P. J., Holbrook, N. M., Burns, M. J., Zwieniecki, M. A., Cobb, A. R., Brodribb, T. J., ... Sack, L. (2012). Measurements of stem xylem hydraulic conductivity in the laboratory and field. Methods in Ecology and Evolution, 3(4), 685-694. doi: 10.1111/j.2041210X.2012.00204.x

Nardini, A., Dimasi, F., Klepsch, M., \& Jansen, S. (2012). Ion-mediated enhancement of xylem hydraulic conductivity in four Acer species: relationships with ecological and anatomical features. Tree Physiology, 32(12), 1434-1441. doi: 10.1093/treephys/tps107 
Neufeld, H. S., Grantz, D. A., Meinzer, F. C., Goldstein, G., Crisosto, G. M., \& Crisosto, C. (1992). Genotypic variability in vulnerability of leaf xylem to cavitation in water-stressed and well-irrigated sugarcane. Plant Physiology, 100(2), 1020-1028. doi: 10.1104/pp.100.2.1020

Niklas, K. J. (1992). Plant biomechanics, an engineering approach to plant form and function (1 ${ }^{\mathrm{a}}$ ed.). Chicago, USA: The University of Chicago Press.

Nobel, P. S. (2009). Physicochemical and environmental plant physiology (4a ed.). Oxford, United Kingdom: Academic Press Inc.

Pammenter, N. W. \& Van der-Willigen, C. (1998). A mathematical and statistical analysis of the curves illustrating vulnerability of xylem to cavitation. Tree Physiology, 18(8-9), 589-593. doi: 10.1093/treephys/18.8-9.589

Patino, S., Tyree, M. T., \& Herre, A. E. (1995). Comparison of hydraulic architecture of woody plants of differing phylogeny and growth form with special reference to free-standing and hemi-epiphytic Ficus species from Panama. New Phytologist, 129(1), 125-134. doi: 10.1111/j.1469-8137.1995.tb03016.x

Pelloux, J., Rusterucci, C., \& Mellerowicz, E. J. (2007). New insights into pectin methylesterase structure and function. Trends in Plant Science, 12(6), 267-277. doi: 10.1016/j.tplants.2007.04.001

Pockman, W. T., Sperry, J. S., \& O’Leary, J. W. (1995). Sustained and significant negative water pressure in xylem. Nature, 378(6558), 715-716. doi: $10.1038 / 378715 \mathrm{a} 0$

Rawlings, J. O., \& Cure, W. W. (1985). The Weibull function as a doseresponse model to describe ozone effects on crop yields. Crop Science, 25(5), 807-814. doi:10.2135/cropsci1985.0011183X002500050020x

Renner, O. (1925). Zum Nachweis negativer drucke im gefa "sswasser bewurzelter holzgewa" chse. Flora, 119(1), 402-408.

Sack, L., Cowan, P. D., \& Holbrook, N. M. (2003). The major veins of mesomorphic leaves revisited: tests for conductive overload in Acer saccharum (Aceraceae) and Quercus rubra (Fagaceae). American Journal of Botany, 90(1), 32-39. doi: 10.3732/ajb.90.1.32.

Sack, L. \& Frole, K. (2006). Leaf structural diversity is related to hydraulic capacity in tropical rainforest. Ecology, 87(2), 483-491. doi: 10.1890/05-0710

Sack, L. \& Holbrook, N. M. (2006). Leaf hydraulics. Annual Review of Plant Biology, 57(1), 361-381. doi: 10.1146/annurev.arplant.56.032604.144141

Salazar, A. \& Gamboa, A. (2013). Importancia de las pectinas en la dinámica de la pared celular durante el desarrollo vegetal. REB. Revista de Educación Bioquímica, 32(2), 67-75.
Salisbury, F. B., \& Ross, C. W. (1992). Plant physiology. (4a ed.). California, USA: Wadsworth

Salleo, S., Hinckley, T. M., Kikuta, S. B., Lo Gullo, M. A., Weilgony, P., Yoon, T. M., \& Richter, H. (1992). A method for inducing xylem emboli in situ: Experiments with a field-grown tree. Plant, Cell and Environment, 15(4), 491-497. doi: 10.1111/j.13653040.1992.tb01001.x

Sane, S. P. \& Singh, A. K. (2011). Water movement in vascular plants: a primer. Journal of the Indian Institute of Science, 91(3), 233-242.

Schenk, H. J., Espino, S., Romo, D. M., Nima, N., Do, A. Y. T., Michaud, J. M., ... Jansen, S. (2017). Xylem surfactants introduce a new element to the cohesion-tension theory. Plant Physiology, 173(2), 1177-1196. doi: 10.1104/pp.16.01039

Schenk, H. J., Steppe, K., \& Jansen, S. (2015). Nanobubbles: a new paradigm for air-seeding in xylem. Trends in Plant Science, 20(4), 199-205. doi: 10.1016/j.tplants.2015.01.008

Scholander P. F., Hammel H. T., Bradstreet E. D., A., \& Hemmingsen, E. A. (1965). Sap pressure in vascular plants negative hydrostatic pressure can be measured in plants. Advancement of Science, 148(3668), 339-346. doi: 10.1126/science.148.3668.339

Scoffoni, C., Rawls, M., McKown, A., Cochard, H., \& Sack, L. (2011). Decline of leaf hydraulic conductance with dehydration: relationship to leaf size and venation architecture. Plant Physiology, 156(2), 832-843. doi: 10.1104/pp.111.173856

Shane, M. W., McCully, M. E., \& Canny, M. J. (2000). Architecture of branch-root junctions in maize: structure of the connecting xylem and the porosity of the pit membranes. Annals of Botany, 85(5), 613-624 doi: 10.1006/anbo.2000.1113

Slatyer, K. O. \& Taylor, S. A. (1960). Terminology in plant and soil water relations. Nature, 187, 922-924.

Sperry, J. S. (1986). Relationship of xylem embolism to xylem pressure potential, stomatal closure, and shoot morphology in the palm Rhapis excelsa. Plant Physiology, 80(1), 110-116. doi: $10.1104 /$ pp.80.1.110

Sperry, J. S., Donnelly, J. R., \& Tyree, M. T. (1988). A method for measuring hydraulic conductivity and embolism in xylem. Plant, Cell and Environment, 11(1), 35-40. doi: 10.1111/j.13653040.1988.tb01774.x

Sperry, J. S. \& Saliendra, N. Z. (1994). Intra-and inter-plant variation in xylem cavitation in Betula occidentalis. Plant, Cell and Environment, 17(11), 1233-1241. doi: 10.1111/j.1365-3040.1994.tb02021.x

Sperry, J. S., Saliendra, N. Z., Pockman, W. T., Cochard, H., Cruiziat, P., Davis, S. D., ... Tyree, M. T. (1996). New evidence for large negative xylem pressures and their measurement by the pressure 
chamber method. Plant, Cell and Environment, 19(4), 427-436. doi: 10.1111/j.1365-3040.1996.tb00334.x

Stiller, V. \& Sperry, J. S. (1999). Canny's compensating pressure theory fails a test. American Journal of Botany, 86(8), 1082-1086. doi: $10.2307 / 2656969$

Stiller, V. \& Sperry, J. S. (2002). Cavitation fatigue and its reversal in sunflower (Helianthus annuus L.). Journal of Experimental Botany, 53(371), 1155-1161. doi: 10.1093/jexbot/53.371.1155

Streeter, L., Wylie, E., \& Bedford, K. (2000). Mecánica de fluidos (9a ed.). Santafé de Bogotá, Colombia: Mc. Graw Hill.

Taiz, L. \& Zeiger, E. (2012). Plant Physiology (5a ed.). Sunderland (Massachusetts), USA: Sinauer Associates.

Trakal, L., Martínez-Fernández, D., Vitková, M., \& Komárek, M. (2015). Phytoextraction of metals: modeling root metal uptake and associated processes. En A. A. Ansari, S. S. Gill, R. Gill, G. R. Lanza, \& L. Newman (Eds.), Phytoremediation (pp.69-83) (1a ed.). New York, USA: Springer. doi: 10.1007/978-3-319-10969-5

Trifilò, P., Nardini, A., Raimondo, F., Lo Gullo, M. A., \& Salleo, S. (2011). Ion mediated compensation for drought-induced loss of xylem hydraulic conductivity in field-growing plants of Laurus nobilis L. Functional Plant Biology, 38(7), 606-613. doi: 10.1071/FP10233

Tyree, M. T. \& Ewers, F. W. (1991). Tansley Review No. 34. The hydraulic architecture of trees and other woody plants. New Phytologist, 119(34), 345-360. doi: 10.1111/j.14698137.1991.tb00035.x

Tyree, M. T., Nardini, A., \& Salleo, S. (2000). Hydraulic architecture of whole plants and single leaves. In M. Labrecque (Ed.), L'arbre 2000 the Tree (pp. 215-221). Montreal, Canada: Isabelle Quentin Publisher.

Tyree, M. T. \& Sperry, J. S. (1989). Vulnerability of xilem to cavitation and embolism. Annual Review of Plant Physiology, 40(1), 19-38. doi: 10.1146/annurev.pp.40.060189.000315

Tyree, M. T. \& Yianoulis, P. (1980). The site of water evaporation from sub-stomatal cavities, liquid path resistances and hydroactive stomatal closure. Annals of Botany, 46(2), 175-193. doi: 10.1093/oxfordjournals.aob.a085906

Tyree, M. T., \& Zimmermann, M. H. (2002). Xylem structure and the ascent of sap. ( $2^{\mathrm{a}}$ ed.). Berlin, Germany: Springer-Verlag Berlin Heidelberg.
Van den Honert, T. H. (1948). Water transport in plants as a catenary process. Discussions of the Faraday Society, 3, 146-153. doi: 10.1039/DF9480300146

Van Doorn, W. G., Hiemstra, T., \& Fanurakis, D. (2011). Hydrogel regulation of xylem water flow: an alternative hypothesis. Plant Physiology, 157(4), 1642-1649. doi: 10.1104/pp.111.185314

Wheeler, J. K., Huggett, B. A., Tofte, A, N., Rockwell, F. E., \& Holbrook, N. M. (2013). Cutting xylem under tension or supersaturated with gas can generate PLC and the appearance of rapid recovery from embolism. Plant, Cell and Environment, 36(11), 1938-1949. doi: 10.1111/pce.12139

Willats, W. G., McCartney, L., Mackie, W., \& Knox, J. P. (2001). Pectin: cell biology and prospects for functional analysis. Plant Molecular Biology, 47(1-2), 9-27. doi: 10.1023/A:1010662911148

Zimmermann, M. H. (1983). Xylem structure and the ascent of sap. (1a ed.). Berlin, Germany: Springer-Verlag.

Zimmermann, U., Schneider, H., Wegner, L. H., \& Haase, A. (2004). Water ascent in tall trees: does evolution of land plants rely on a highly metastable state? New Phytologist, 162(3), 575-615. doi: 10.1111/j.1469-8137.2004.01083.x

Zwieniecki, M. A., Melcher, P. J., \& Holbrook, N. M. (2001). Hydrogel control of xylem hydraulic resistance in plants. Science, 291(5506), 1059-1062. doi: 10.1126/science.1057175

Manuscrito recibido el 1 de agosto de 2018

Aceptado el 21 de marzo de 2019

Publicado el 13 de diciembre de 2019

Este documento se debe citar como:

Alemán-Sancheschúlz, G., Solano, E., Terrazas, T., \& LópezPortillo, J. (2019). La arquitectura hidráulica de las plantas vasculares terrestres, una revisión. Madera y Bosques, 25(3), e2531828. doi: 10.21829/myb.9019.2531828

Madera y Bosques por Instituto de Ecología, A.C. se distribuye bajo una Licencia Creative Commons Atribución-NoComercialCompartirlgual 4.0 Internacional. 